\title{
Fetal Circulation with Increased Nucleated Erythrocytes
}

National Cancer Institute

\section{Source}

National Cancer Institute. Fetal Circulation with Increased Nucleated Erythrocytes. NCI

Thesaurus. Code C118141.

Increased nucleated red blood cells within the fetal circulation. 